\title{
Tourism Strategy of IP Image Cultural Forest Countryside Driven by Data
}

\author{
Huang Fan,Wang Yanqi \\ School of Fine Arts and Art Design, Kunming University, Kunming, Yunnan, China
}

\begin{abstract}
:
This paper discusses the sustainable development of forest and rural tourism from the perspective of regional culture. This paper points out that there is a dialectical relationship between regional culture and the development of forest and rural tourism. This paper focuses on the impact of regional culture on the sustainable development of forest and rural tourism. On this basis, this paper analyzes the restrictive factors of the sustainable development of forest and rural tourism in China through AHP analysis and data-driven methods, and puts forward the basis, steps and ideas for the establishment of forest and rural tourism cultural mechanism. Finally, the sustainable development of forest and rural tourism in a certain area of China is studied. The experimental results show that the research results of this paper have a certain reference value for the research of forest rural tourism strategy driven by data.
\end{abstract}

Keywords: Forest Tourism, Forestry, Data Driven, Cultural Strategy

\section{INTRODUCTION}

Since the late 1990s, the global tourism industry is breaking through the traditional single tourism product model and developing in the direction of product diversification, tourism appeal diversification and promotion model [1-2]. The rise of rural tourism is one of the striking phenomena. Due to the repulsive effect of urban culture, quiet and simple villages, especially those rural areas with strong local characteristics, folk customs and profound cultural heritage, increasingly show their strong tourism attraction [3.]. The vast countryside moves from the background of tourism activities to the front stage of tourism activities. Rural ecology, rural scenery, rural folk customs and rural life have become the objects of tourism activities. It enriches the series of tourism activities and products, makes the experience of tourists more comprehensive, makes the scope and force of tourism to promote regional economic development wider, and makes the tourism industry itself obtain greater development space. 
Article History: Received: 28 October 2021 Revised: 05 December 2021 Accepted: 10 January 2022 Publication: 28 February 2022

\section{RESEARCH ON THE INFLUENCE OF REGIONAL CULTURE ON RURAL TOURISM DEVELOPMENT}

1.Maintaining the difference of regional culture is the fundamental to maintain the rural character.

The process of cultural development and dissemination has certain spatial and regional characteristics, and there are many differences even in the same ethnic region; The belt and inter provincial nature of natural landscape is the specific manifestation of regional nature. Regional culture is the spatial classification of culture and the cohesion and fixation of type culture in spatial region [4-5]. Today's world has entered a culture sensitive era, and regional cultural differences particularly affect all aspects of social development. When people pay more and more attention to cultural quality and pursue spiritual resources, the value of regional culture, a unique spiritual resource, is particularly prominent [6]. For tourism, due to its remote nature, the farther the distance between people's residence and tourism destination, the greater the regional cultural differences, the more it will stimulate people's curiosity and subjective imagination, so as to promote tourism motivation. In a sense, the driving force of tourism comes from difference to a great extent. The success of tourism depends on the understanding and promotion of differences in different cultural and social regions.

Rural tourism is usually described as a kind of related tourism activities in rural areas with various types of pastoral scenery as the background [7-8]. It can take any unconventional organizational form, or it can be a carefully combined tourism product. This process is the process of organizing a series of rural tourism activities and creating a profound rural tourism experience. However, both formal and informal rural tourism activities are inseparable from the quiet and peaceful rural environment with open space and simple folk customs.

Sharpley believes that the development of rural tourism is a rural development economic activity based on the rural environment. This means that "rural nature is the core and unique buying point of the overall promotion of rural tourism". Then, since rural tourism occurs in rural areas, it is a tourism type based on the special appearance of the rural world, small business scale, open space and sustainable development. Then maintaining the "rural nature" of rural areas has become the key means to realize the sustainable development of rural tourism. Among them, the maintenance of rural natural environment has been recognized and implemented, but the rural cultural characteristics have not been effectively guaranteed. Only by properly inheriting and developing the unique regional culture in rural areas can we better maintain one of the important characteristics of Rural Tourism - rural nature.

2.Regional culture has an important impact on tourism decision-making

There is no doubt that an important purpose of people's tourism is to get rid of the monotonous and rigid life mode day after day, enjoy life outside home life, contact new things and feel the novelty that can't be felt in daily life. However, not any place or any tourism 
Article History: Received: 28 October 2021 Revised: 05 December 2021 Accepted: 10 January 2022 Publication: 28 February 2022

product can be recognized by tourists [9]. Only those with prominent attributes and strong stimulation to tourists can be selected as a cognitive object. The distinctive and unique cultural atmosphere in regional culture is one of the important factors to attract tourists' attention. People in other cultural regions must be very eager to travel and experience the cultural region with distinctive characteristics. Therefore, in the cognitive process of tourists and in their decision-making process, the cultural atmosphere of the region where the tourism products are located, that is, the tourism reception place, is a focus that tourism enterprises should firmly grasp in their publicity and planning. First, it is the "wandering soul" that can penetrate into all cognitive links and where people can feel the freshness most.

China's regional cultures have identity, but also differences, which are mainly reflected in folk customs. This has just become the characteristics of regional culture, which makes regional cultures form a situation of similarities, differences and similarities. Therefore, the comparable performance of regional culture enables tourists to mobilize the accumulation of all knowledge and experience to perceive the tourism products of a regional culture, so as to make the final decision. Tourism enterprises should start with the comparability of regional culture and pay attention to the selectivity of tourism perception from the perspective of tourism psychology, so as to do a good job in relevant publicity and scheduling. The so-called selectivity of tourism perception refers to a few stimuli that can attract attention. There is a process of information filtering and screening. It is regular for people to screen out perceptual objects from the background [10]. These laws are mainly difference law and combination law, which coincide with the difference and comparability of regional culture.

China's regional culture is a culture with its own characteristics, which is gradually accumulated in the long historical development by the differences in ten historical origins, geographical environment and economic conditions. Regional culture has great historical traction. People often want to feel an old glory or historical atmosphere. This is also the exciting side of the tourism project. It can not only meet people's purpose of seeking knowledge, learning and investigation, but also let people experience the emotional experience of changing things, changing the world, changing the past and so on. In short, if we fully excavate the connotation of history and history in regional culture and take it as the background and support of tourism products, tourism products will live. It will carry out spiritual communication with tourists with rich "expression" and charm, so that such tourism will be attractive and make people linger.

\section{ESTABLISHMENT OF CULTURAL MECHANISM FOR SUSTAINABLE DEVELOPMENT OF RURAL TOURISM}

1.The basis of cultural mechanism for sustainable development of rural tourism

The purpose of tourists' rural tourism is to obtain a more profound tourism experience and 
Article History: Received: 28 October 2021 Revised: 05 December 2021 Accepted: 10 January 2022 Publication: 28 February 2022

hope to completely relax their body and mind or even understand the true meaning of life in a quiet and simple countryside and in a cultural atmosphere different from their usual life. The establishment of rural tourism cultural mechanism should make rural tourism fully reflect rural characteristics, rural style, local culture and history, and help tourists obtain a good tourism experience.

Tourism investment is used to support the rural economy, but it should seek development in a broader geographical scope. At the same time, guide the flow of tourists to be more stable, avoid traffic congestion and damage to resources due to environmental erosion and overuse, and enhance the impact on economy and other aspects. The establishment of cultural mechanism is to ensure that tourism activities play a real role in promoting the local economy and ensure its healthy, rapid and sustainable growth.

The establishment of cultural mechanism should strive to create a harmonious and good exchange atmosphere between rural tourism destination residents and tourists, provide an best platform for tourists to understand local culture, and try their best to avoid the "stage" tendency of culture.

Through the establishment of cultural mechanism, standardize and guide the advertising, information and marketing activities adopted by rural tourism, and maintain cultural characteristics in the selection of marketing means and the determination of marketing content. On the one hand, it can deepen residents' understanding and recognition of local resources and culture and create a friendly and enthusiastic tourism atmosphere. On the other hand, it can also deepen tourists' understanding of the countryside, enhance people's attention to the countryside and effectively affect people's tourism decision-making.

2.Steps of establishing cultural mechanism for sustainable development of rural tourism

1) The basic work of establishing a scientific rural tourism cultural development mechanism is to carefully investigate the rural cultural landscape. To be comprehensive and systematic, cultural investigation must be universal. In addition, cultural investigation must be profound, not just some superficial symbols, colors and mouth numbers, but should go deep into adults' values, intentions, habits and ideas, and see the real cultural phenomenon, so as to ensure that we can truly grasp the regional cultural personality and its unique cultural temperament. 2) Accurate cultural analysis and evaluation of local culture is an important step in establishing a cultural mechanism for the development of rural tourism. The goal of cultural analysis is to clearly grasp the regional cultural environment, humanistic situation, cultural characteristics and cultural structure, content, form and system. 3) Positioning regional culture is the foothold of establishing the cultural mechanism of rural tourism development. The positioning of regional culture generally focuses on the following three questions: what position does the region with this culture occupy in its region, the whole country and even the world; What are the characteristics and advantages of the regional culture, and what are the main differences between the regional culture and the adjacent regional culture; How to position correctly. 4) To 
Article History: Received: 28 October 2021 Revised: 05 December 2021 Accepted: 10 January 2022 Publication: 28 February 2022

clarify the positioning of regional culture, we should formulate the cultural mechanism of rural tourism development in combination with the reality of rural tourism development. The purpose of establishing the mechanism is to ensure the smooth development of rural tourism activities; Provide tourists with a beautiful tourism experience; Protect the ecological, social and cultural environment of rural tourism destinations; Enhance the communication and understanding between tourists and destination residents. 5) A scientific development mechanism of rural tourism culture must have a practical implementation plan. It mainly includes three links: concept renewal, manager's exemplary role, continuous revision and improvement. As shown in Figure 1.

3.On the establishment of cultural mechanism for sustainable development of rural tourism

As shown in Table 1, in the education level survey of residents in the Yangtze River Delta, $28.2 \%$ have "Bachelor's degree or above", and 27.4\% have college degree. This shows that the cultural quality of residents in the Yangtze River Delta is generally high, and the corresponding requirements for all aspects of tourism destinations will be high, especially in software such as service quality and cultural connotation of tourism products.

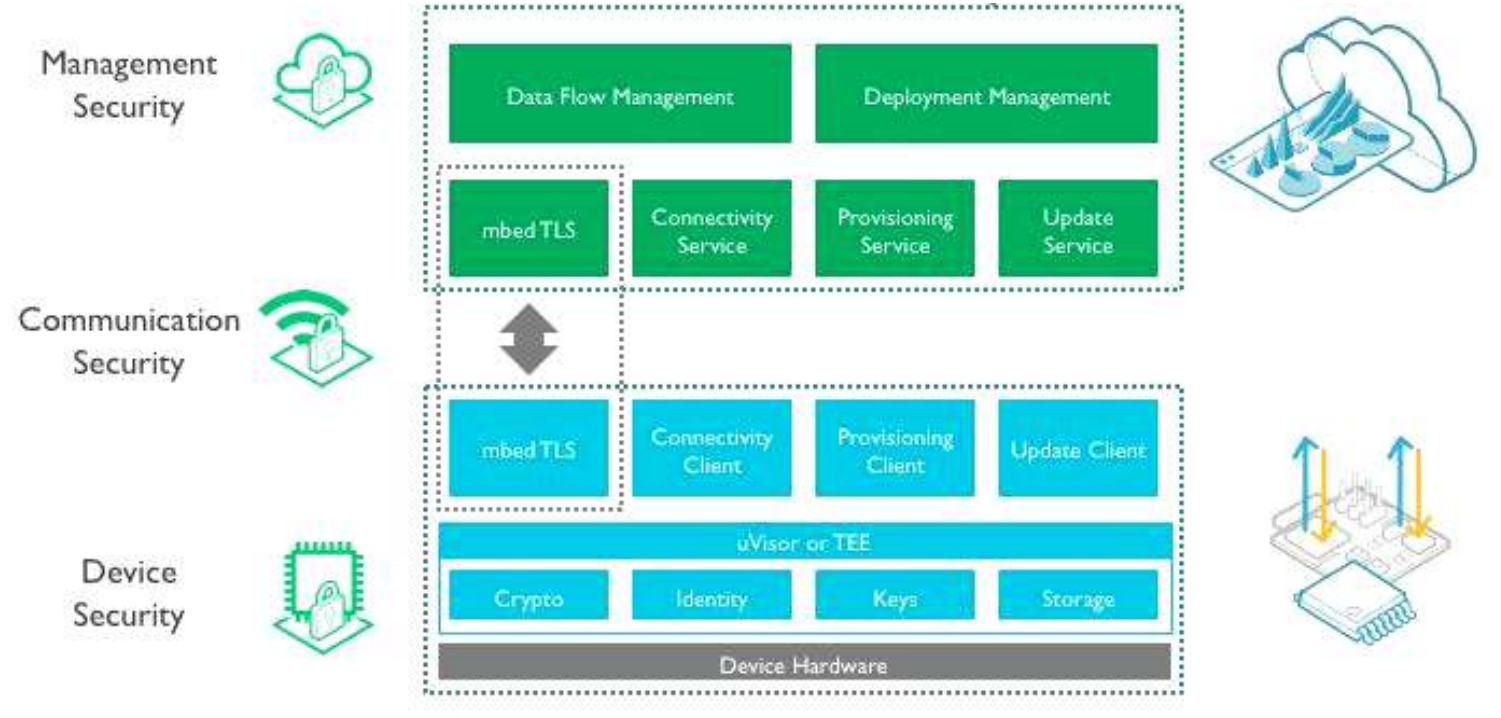

Fig 1: Steps of establishing cultural mechanism for rural tourism development

TABLE I. Survey and statistics of residents' educational level in the Yangtze River Delta

\begin{tabular}{|c|c|c|}
\hline DEGREE OF EDUCATION & $\begin{array}{c}\text { NUMBER OF } \\
\text { PEOPLE }\end{array}$ & PERCENTAGE (\%) \\
\hline BACHELOR DEGREE OR ABOVE & 141 & 28.2 \\
\hline JUNIOR COLLEGE & 137 & 27.4 \\
\hline
\end{tabular}


Article History: Received: 28 October 2021 Revised: 05 December 2021 Accepted: 10 January 2022 Publication: 28 February 2022

\begin{tabular}{|c|c|c|}
$\begin{array}{c}\text { HIGH SCHOOL OR TECHNICAL } \\
\text { SECONDARY SCHOOL }\end{array}$ & 146 & 29.1 \\
\hline JUNIOR HIGH SCHOOL & 25 & 5.1 \\
\hline PRIMARY SCHOOL AND BELOW & 5 & 1 \\
\hline
\end{tabular}

In the development and construction of rural tourism products, we should highlight the characteristics of wood and soil culture, and deeply excavate the cultural connotation of rural tourism resources in the design of rural embedded dam day. Maintain the authenticity of the rural environment, create the local flavor and atmosphere of traditional culture, increase cultural content, increase knowledge and participation, retain tourists, prolong their stay, and establish the concept of "making high-quality products". We should closely combine rural environmental tourism with cultural tourism.

The integration of tourism culture is not the simple addition of several cultures, but the continuous conflict and integration between tourism meta culture (referring to the tourism destination culture that attracts tourists) and modern culture and foreign culture in tourism activities, until it is transformed into the process and result of tourism culture satisfactory to tourists. As a result, the integration of tourism culture depends on whether the culture experienced by tourists finally meets the requirements of tourists and sustainable development. If so, it shows that the integration of tourism culture is successful. As a process, tourism culture integration refers to the sum of various relationships and phenomena in the process of continuous conflict and integration between tourism meta culture, intermediary culture and tourists' own culture until it is transformed into a new tourism culture attraction satisfied by tourists (see Figure 2).

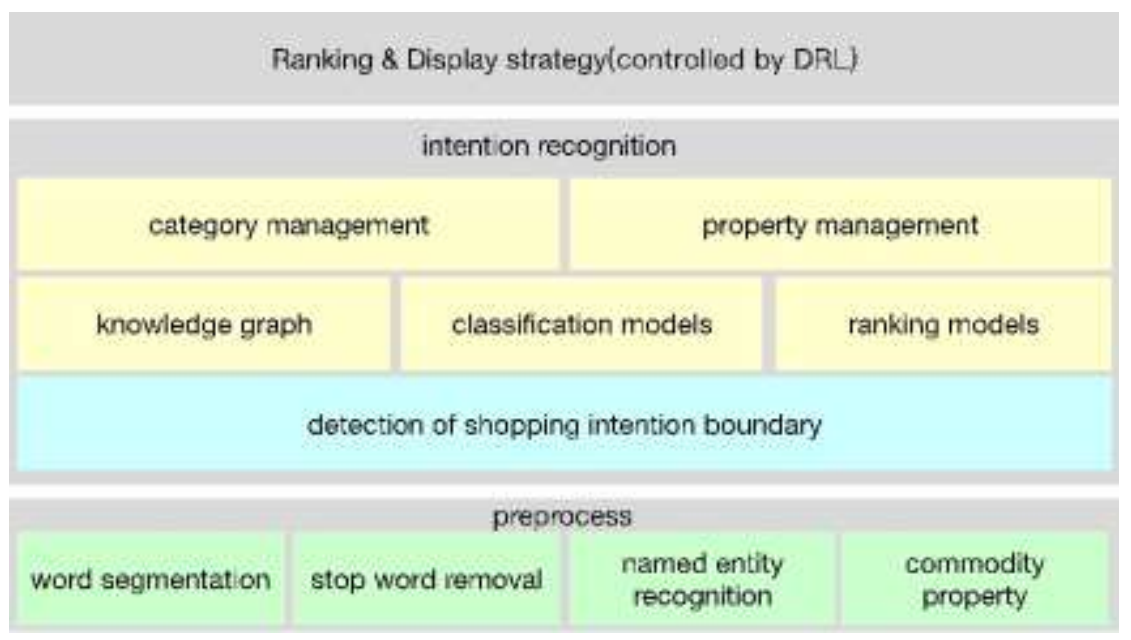

Fig 2: The formation process of new cultural attractions in rural areas 
Culture is a constantly developing and changing thing, so is tourism culture. In the process of rural tourism development, we must constantly pay attention to and promote the integration of rural tourism culture, form new cultural attractions satisfactory to tourists, and make sustainable cultural utilization to achieve the purpose of sustainable development of rural tourism.

Rural hospitality culture is the comprehensive expression of rural culture in the attitude, mode and content of a foreign tourist. It includes rural traditional culture, agricultural culture, folk culture and other cultural components. The basic content of rural hospitality culture includes reception etiquette, social atmosphere and rural landscape. Reception etiquette and social atmosphere are the humanistic carrier of rural hospitality culture and the most important factor for tourists to obtain experience.

\section{CONCLUSION}

There is a dialectical relationship between regional culture and rural tourism. In the process of rural tourism development, we should carefully investigate and analyze the regional culture and formulate the cultural development mechanism of rural tourism, so as to realize the sustainable development of rural tourism. The establishment of rural tourism cultural mechanism starts from several aspects: (1) strengthening macro management and guidance; (2) Excavate the local cultural characteristics and create a distinctive overall rural landscape image; (3) For the cultural design of rural tourism products, tourism projects should be hierarchical and serialized; (4) Promote the integration of tourism culture and create new cultural attractions for rural tourism; (5) Cultivate rural hospitality culture and create more communication opportunities for tourists and local residents.

\section{ACKNOWLEDGEMENTS}

"Research on innovative design of cultural and creative products in Yunnan under the trend of cultural tourism integration -- Taking Dali as an example" from the research subject of the Department of Education of Yunnan province (Project No.:2021j0737).

\section{REFERENCES}

[1] Du Peng, Yang Lei. Research on Construction System and Development Strategy of Smart Tourism System . Science and Technology Management Research, 2013, 23: 44-49

[2] Liu Junlin, Chen Xiaolian. Construction and Application of Intelligent Tourism Disaster 
Article History: Received: 28 October 2021 Revised: 05 December 2021 Accepted: 10 January 2022 Publication: 28

February 2022

Early Warning and Disaster Relief Platform . Economic Geography, 2011, 31 (010): 17451749

[3] Xu Feifei, Huang Lei. A Study on the Willingness to Use Smart Tourism System in Scenic Spots: Based on the Integrated Tam and Ttf Model . Journal of Tourism, 2018, V.33; No.264 (08): 108-117

[4] Wu Baogang. Application of Big Data in Smart Tourism Management: a Review of Tourism Management . Science and Technology Management Research, 2020, V.40; No.448 (06): 281-281

[5] Jin Weidong. Smart Tourism and the Construction of Tourism Public Service System . Tourism Journal, 2012 (02): 6-7

[6] Wang Zhimin. Research on the Synergy Between Regional Tourism Industry and Technological Innovation -- a Case Study of Jiangsu Province . World Geographic Research, 2016, 25 (6): 158-165

[7] Liao Shuhong. New Thinking on the Establishment of Beautiful Rural Creative Park . North China Agricultural Journal, 2010, 25 (z3): 000181-182

[8] Weng Gangmin, Li Weijin. Smart Tourism and the Construction of Regional Tourism Innovative Development Model -- Taking Qinhuangdao As an Example . Urban Development Research, 2014, 21 (5): 17-22

[9] Li Yunpeng, Hu Zhongzhou, Huang Chao . Discussion on Smart Tourism from the Perspective of Tourism Information Service . Tourism Journal, 2014, 92(2):1-11.

[10] Wu Chanti. Research on Influencing Factors of User Satisfaction of Tourism Websites -Taking Tongcheng.com As an Example . Enterprise Economy, 2017 (11): 138-143 